\title{
Factors associated with noncompletion of latent tuberculosis infection treatment in an inner-city population in Edmonton, Alberta
}

\author{
Kathy Malejczyk MD¹, Jennifer Gratrix RN MSc${ }^{2}$, Avril Beckon RN³ , Danusia Moreau RN4, \\ Gwenna Williams LPN ${ }^{3}$, Dennis Kunimoto MD ${ }^{5}$, Rabia Ahmed MD
}

\begin{abstract}
K Malejczyk, J Gratrix, A Beckon, et al. Factors associated with noncompletion of latent tuberculosis infection treatment in an inner-city population in Edmonton, Alberta. Can J Infect Dis Med Microbiol 2014;25(5):281-284.
\end{abstract}

A limited number of studies have been published that examine treatment completion rates and interventions used to increase treatment completion within an inner-city population. The purpose of the present study was to determine the rate of latent tuberculosis infection (LTBI) treatment completion in an inner-city population in Edmonton, Alberta, and to identify factors that correlated with treatment completion. A retrospective chart review was conducted involving patients who started LTBI treatment between January 1, 2005 and December 31, 2010 in Edmonton's inner city. A total of 77 patients started treatment and 57 (74\%) patients completed LTBI treatment. Homelessness was the only variable that was significantly associated with incomplete treatment (OR 8.0 [95\% CI 1.4 to 45.6]) and it remained significant when controlling for drug use (adjusted OR 6.5 [95\% CI 1.1 to 38.8]). While the present study demonstrated treatment completion rates comparable with or better than those described in the general population, it highlighted the need for continued emphasis on interventions aimed at improving outcomes within homeless populations.

Key Words: Adherence; Completion; Homeless individuals; Inner city; Intensive case management; Latent tuberculosis infection

$A$ pproximately one-third of the world's population is estimated to A be infected with latent Mycobacterium tuberculosis, and approximately $10 \%$ of these individuals are expected to go on to develop active disease (1). This makes treatment for latent tuberculosis (TB) infection (LTBI) an important strategy for TB control programs. However, the effectiveness of LTBI treatment depends on treatment adherence. Overall, treatment adherence has ranged from $22 \%$ to $90 \%$ in various risk groups (2).

In countries with low TB incidence, the challenge of effective LTBI treatment lies in high-risk groups and settings. Injection drug use, excessive alcohol use, unemployment and homelessness have been associated with failure to complete preventive treatment (2). Strategies that have demonstrated some effectiveness in improving adherence within these high-risk groups include directly observed therapy, monetary incentives, educational programs or some combination thereof (2-10). Additionally, shorter-course treatment regimens have been increasingly associated with improved adherence (3).

\section{Les facteurs associés à l'inachèvement du traitement contre l'infection tuberculeuse latente dans la population d'un quartier pauvre d'Edmonton, en Alberta}

Quelques études publiées ont porté sur le taux d'achèvement des traitements et les interventions utilisées pour accroître cet achèvement dans la population d'un quartier pauvre. La présente étude visait à déterminer le taux d'achèvement du traitement contre l'infection tuberculeuse latente (ITL) dans la population d'un quartier pauvre d'Edmonton, en Alberta, et déterminer les facteurs qui corrélaient cet achèvement. Les chercheurs ont effectué une recherche rétrospective dans les dossiers des patients qui avaient un amorcé un traitement contre l'ITL entre le $1^{\text {er }}$ janvier 2005 et le 31 décembre 2010 dans un quartier pauvre d'Edmonton. Au total, 77 patients ont amorcé le traitement contre l'ITL et 57 patients ( $74 \%$ ) l'ont terminé. L'itinérance était la seule variable qui s'associait de manière significative à un traitement incomplet (RR 8,0 [95 \% IC 1,4 à 45,6]), et elle demeurait significative lorsqu'on tenait compte de la consommation de drogue (RR rajusté 6,5 [95 \% IC 1,1 à 38,8]). La présente étude faisait état d'un taux d'achèvement comparable ou meilleur à celui décrit dans la population générale, mais faisait ressortir la nécessité d'insister constamment sur des interventions visant à améliorer les résultats cliniques dans les populations d'itinérants.

A limited number of studies have been published that examine treatment completion rates and interventions used to increase treatment completion within an inner-city population (3). The purpose of the present study was to determine the rate of LTBI treatment completion within an inner-city population in Edmonton, Alberta, and to identify factors that correlate with treatment completion.

Study setting and population

\section{METHODS}

Edmonton is a northern Canadian city with a population of 1,024,820; $18.5 \%$ of the population are immigrants (11). The homeless population is estimated to be 3079 and is concentrated in the inner city of Edmonton (12). A central inner-city health clinic provides multidisciplinary care to this population. A significant proportion of patients are HIV- and/or hepatitis C-infected, homeless or underhoused, working poor or unemployed, report substance use, and are Aboriginal or recent immigrants. The clinic is located in the inner city and provides further outreach services within the community to locate patients (including to local shelters,

${ }^{1}$ Department of Laboratory Medicine, Medical Microbiology, Regina Qu'Appelle Health Region, Regina, Saskatchewan; ${ }^{2}$ STI Centralized Services; ${ }^{3}$ Edmonton Tuberculosis Clinic; ${ }^{4}$ Central TB Services, Alberta Health Services; ${ }^{5}$ Department of Medicine, University of Alberta, Edmonton, Alberta

Correspondence: Dr Kathy Malejczyk, Department of Laboratory Medicine, Medical Microbiology, Regina Qu'Appelle Health Region, 4862 Upson Road, Regina, Saskatchewan S4W 0A6. Telephone 306-501-8078, fax 306-766-4640, e-mail klabedz@ualberta.ca 
drop-ins, homes, etc). The clinic model focuses on intensive outreach case management of all cases of active TB and LTBI, focusing on tracking and adherence-coaching interventions, education, nonmonetary incentives and health promotion strategies aimed at improving barriers to accessing health care and addressing social determinants of health.

\section{Demographic and clinical characteristics}

A retrospective review of all patients diagnosed with LTBI between January 1, 2005 and December 31, 2010, at the inner-city outreach TB clinic was completed. Demographic, clinical and treatment data were extracted from the Integrated Public Health Information System and from patient health care charts. Patients were excluded from the study if a LTBI treatment regimen other than isoniazid (INH) or rifampin was used.

\section{Definitions}

The diagnosis of LTBI was made in accordance with criteria described in the Canadian Tuberculosis Standards (6th edition) (9). Completion of LTBI was defined by completing a specified number of doses within a specified time period for each regimen. Completion of a nine-month daily INH regimen was defined as 270 doses within 12 months, and completion of a nine-month, twice-per-week INH regimen was defined as 76 doses within 12 months. Completion of a four-month rifampin regimen was defined as 120 doses within a six-month period. Completion of a six-month rifampin and INH twice weekly regimen was defined as 52 doses within a nine-month period (13). TB public health nurses assessed compliance of self-administered treatment based on patient self-reporting and prescription refills.

\section{Data analysis}

Frequencies and proportions were calculated for categorical variables. The median and interquartile range was calculated for continuous variables. The $\chi^{2}$ or Fisher's exact (depending on cell size) and the MannWhitney test were used to detect differences between individuals who had completed treatment and those who had not. Bivariate logistic regression was completed using variables significant $(P>0.10)$ at the univariate level. Analyses were completed using SPSS version 19 (IBM Corporation, USA). The present study obtained ethics approval (ID Pro00018631) from the Health Research Ethics Board, a conjoint University of Alberta, Alberta Health Services and Covenant Health Research Ethics Boards designated under the Health Information Act.

\section{RESULTS}

A total of 85 patients attending the inner-city TB program were identified to have LTBI and offered treatment between January 1, 2005 through to December 31, 2010. Of these, 90.6\% ( $n=77)$ accepted treatment. There were no significant differences in sex, ethnicity, homelessness, or alcohol and drug use between those who accepted treatment and those who refused. Of the 77 patients who were started on treatment for LTBI, tuberculin skin test was positive in 72 (94.7\%). Of the five remaining patients, the diagnosis of LTBI was based on positive interferon gamma release assay $(n=1)$ and abnormal chest $x$-ray compatible with previous granulomatous infection $(n=4)$.

Table 1 shows the demographic and clinical characteristics of the study population. Overall, patients were predominantly male $(n=48[62.3 \%])$, Canadian-born Aboriginal $(n=32[45.1 \%])$ or foreign-born $(n=23[32.4 \%])$, and unemployed $(n=58$ [69.4\%]). In addition, some patients were homeless $(n=7[9.1 \%])$, incarcerated at the start of treatment $(n=13[17.1 \%])$, and reported drug and alcohol use $(n=18[25.7 \%]$ and $n=25$ [34.7\%], respectively).

The most common reasons for LTBI treatment included contact with a TB case $(n=33$ [42.9\%]), being immunosuppressed $(n=32[41.6 \%])$, tuberculin skin test conversion $(n=15[19.5 \%])$ and history of incarceration $(n=14[18.2 \%])$. In addition, chest $x$-ray abnormalities were present in $27.3 \%(n=21)$ of patients; $21.1 \%$ $(n=16)$ of patients had 'low-risk scars' defined by the presence of granuloma and $5.7 \%(n=5)$ of patients had 'high-risk' scars defined by upper-lobe fibronodular changes. Nearly one-third $(n=24[31.2 \%])$ of patients were HIV positive and two (2.6\%) had a history of receiving preventive treatment for LTBI.

Three-quarters of patients $(\mathrm{n}=60$ [77.9\%]) were treated using a nine-month INH regimen, $9.1 \%(n=7)$ of patients were treated using a four-month rifampin regimen, and a combined six-month INH and rifampin regimen was used to treat $13.0 \%(n=10)$ patients. Medication delivery was supported by directly observed therapy in $59.5 \%(n=44)$ of patients and, in addition, one-third of patients $(n=23$ [32.4\%]) also received nonmonetary incentives (food supplements, bus tickets or taxi chits to attend appointments) toward treatment completion.

Of the 77 patients that started LTBI treatment, $74 \%(n=57)$ completed treatment. The majority of patients who did not complete their LTBI treatment refused or were noncompliant $(n=12[60 \%])$. The remaining $40 \%$ of patients experienced side effects ( $n=5$ [25\%]), relocated $(n=2[10 \%])$ or were medically advised to stop treatment $(n=1[5 \%])$ with the reason undocumented. Of the five patients who experienced side effects, three had elevated liver enzyme levels and two patients developed a rash.

Through univariate analysis, homelessness was the only variable that was significantly associated with not completing treatment (OR 8.0 [95\% CI 1.4 to 45.6]; P=0.019, Table 1). When drug use was controlled for in the regression model, homelessness remained the only significant factor (adjusted OR 6.5 [95\% CI 1.1 to 38.8]). Incarceration and homeless were mutually exclusive categories and, therefore, none of the homeless populations were on LTBI treatment due to incarceration; thus, this variable was not included in the model. The number of homeless patients in the sample was small $(n=7)$; however, they were more likely to be immunosuppressed $(85.7 \%$ versus 40.0\%; $\mathrm{P}=0.04$ ), and HIV positive (85.7\% versus $25.7 \%$; $\mathrm{P}=0.003$ ). They were also more likely to use alcohol $(71.4 \%$ versus $30.8 \%$; $\mathrm{P}=0.045)$ and although not statistically significant, to use drugs (57.1\% versus $22.2 \% ; \mathrm{P}=0.067$ ). Of the seven homeless patients, five did not complete treatment due to noncompliance $(n=3)$, elevated liver enzyme levels $(n=1)$ and medical advice $(n=1)$.

\section{DISCUSSION}

The present study, conducted at an inner-city health clinic in Edmonton, Alberta, demonstrates that high completion rates of LTBI treatment can be achieved in an inner-city population, with nearly three-quarters $(n=57[74 \%])$ of patients completing their treatment. Although our completion rate is comparable with or better than that described within the general population $(3,8,14-17)$, it exceeds the rates reported among inner-city patients (20\% to $44.6 \%)$ in previous studies $(3,4,17)$.

In our study, the only factor to be negatively associated with treatment completion was homelessness. This finding has been previously documented in other inner-city populations $(3,4,16-18)$. A recent review of the annual TB incidence associated with homelessness in the United States identified an approximately 10 -fold higher rate compared with the general population. Additionally, homeless TB patients were found to have twice the odds of not completing treatment due to being lost to follow-up, having moved or refusing treatment (19).

Homelessness has been associated with individual risk factors that can increase the risk of the development of active TB such as malnutrition, smoking, diabetes, HIV infection and alcohol abuse $(9,20,21)$. The homeless population in our study was more likely to be HIV positive, use alcohol and, although not statistically significant, use drugs. Homeless TB patients also tend to seek care when disease is advanced and highly contagious, with subsequent exposure of a large number of vulnerable individuals to the disease through the shelter system and other sites of aggregation. TB genotyping data also suggest that homelessness is associated with greater risk of transmission $(19,22,23)$. Thus, identification and treatment of homeless individuals with LTBI may provide the greatest opportunity to prevent future cases in this population and underscores the importance of public health outreach strategies (19).

Multiple barriers exist for homeless populations in accessing health care services, despite the fact that Canada has a system of universal 
TABLE 1

Demographic, clinical and treatment characteristics according to latent tuberculosis (TB) infection (LTBI) treatment completion status in Edmonton, Alberta, $n=77$

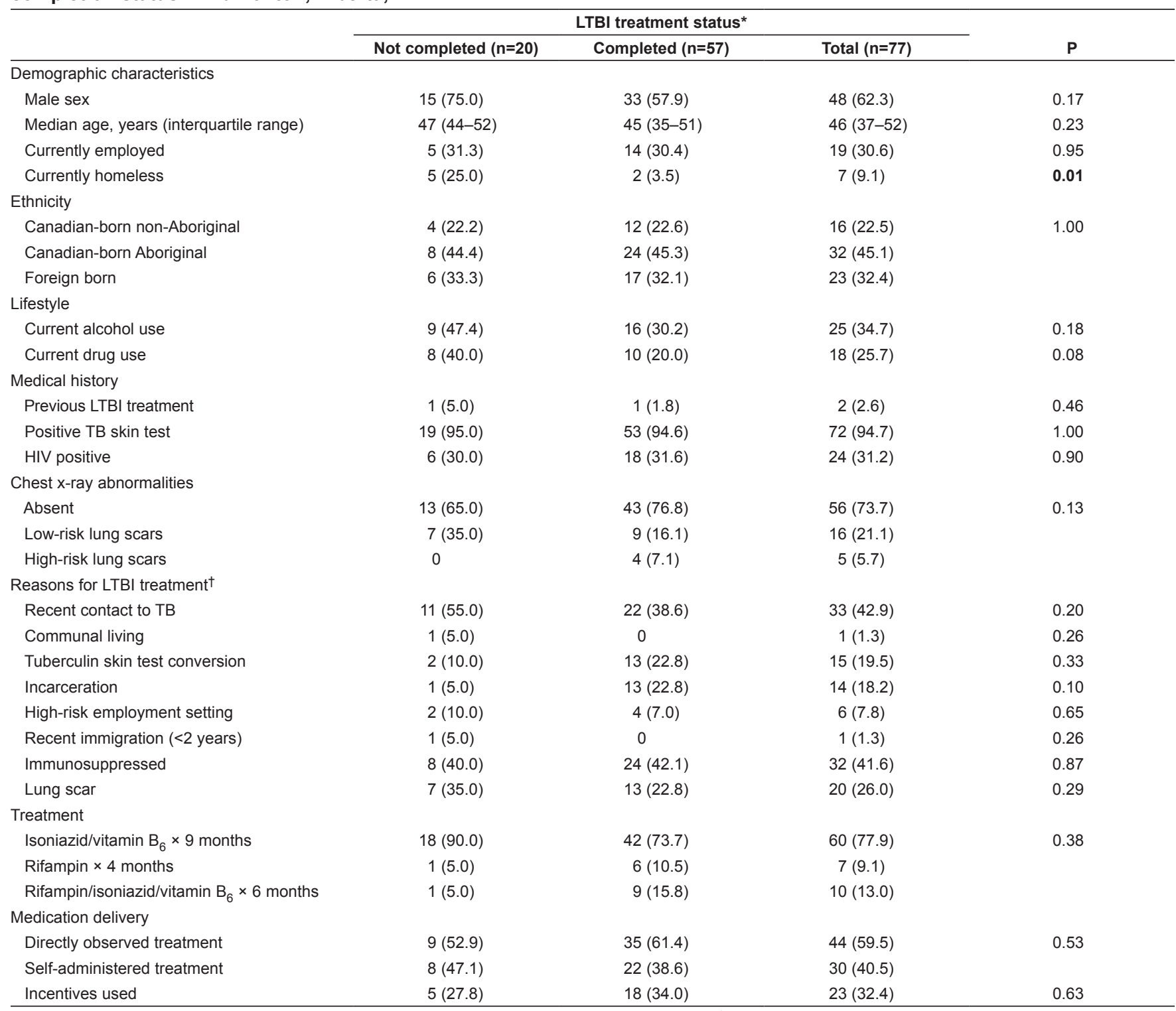

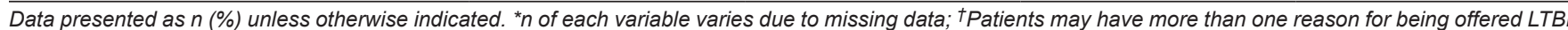

health care insurance (24). First, primary concerns for homeless populations often include housing, food security, employment and income support, rather than their health status $(25-27)$. These competing priorities may impede homeless individuals from using health care services, particularly those perceived as optional or even potentially harmful, as is the case for LTBI treatment. Second, a lack of awareness, information and knowledge about health conditions and available services significantly challenge access to health care and other social services $(7,28)$. Finally, homeless populations experience a significant amount of stigmatization and discrimination within the health care system, leading to a feeling of mistrust for health care providers (28).

A systematic review of adherence studies in the United States and Canada noted suboptimal completion and adherence rates in all high-risk groups; interventions aimed at improving adherence in these groups have been inconsistent (2). Patient characteristics associated with improved adherence include recent exposure to TB, social support and higher level of education (2). Programmatic strategies that have demonstrated some effectiveness in improving adherence within high-risk groups include directly observed therapy, monetary incentives, educational programs, shorter-course treatment regimens or some combination thereof $(2-10)$.

With the exception of monetary incentives, which were not used in our clinic, none of these interventions were significantly associated with increased rates of treatment completion. We attribute our high rate of LTBI completion among this inner-city population, in large part, to the intensive case management model of our clinic, which provides holistic care to the patient to ensure they have consistent access to health care. The model of our clinic seeks to consider the identified barriers to care for homeless populations as well as identified programmatic factors for improving treatment adherence such as directly observed therapy, education and shorter-course regimens.

Our clinic is located centrally at an inner-city community health centre and has an outreach nurse who provides intensive outreach case management focusing on tracking, adherence coaching, education, nonmonetary incentives (including transportation vouchers and dietary supplements), and health promotion strategies aimed at improving barriers to accessing health care and addressing social determinants of health. Additionally, the clinic provides on-site 
appointments with a TB physician, and laboratory and $\mathrm{x}$-ray access with extended hours of operation. The outreach model also aims to include partnerships in providing TB care within inner-city agencies and nongovernmental organizations through providing onsite educational and screening programs. In this setting, it is easier to establish a trusting relationship with the $\mathrm{TB}$ nurse provider to support the client population in following recommendations and adhering to treatment regimes. Moreover, the outreach model creates a 'therapeutic community' and a safe and supportive environment for its members, enabling the community of inner-city agencies and nongovernmental organizations to actively support clients in keeping appointments and adhering to the recommended treatment regimen, thus positively impacting treatment adherence. Such models of intensive case management have been shown to have some success with TB screening and treatment and requires further exploration to improve health care outcomes in this 'hard-to-reach' demographic $(7,29,30)$. Although, programmatically, delivery of care in the outreach model is the same for every patient, the transient nature of the homeless population makes it difficult to consistently track and locate these individuals. As a result, this population does not utilize

\section{REFERENCES}

1. World Health Organization. WHO Annual Report on global TB control-summary. Wkly Epidemiol Rec 2003;78:122-8.

2. Hirsch-Moverman Y, Daftary A, Franks J, Colson W. Adherence to treatment for latent tuberculosis infection: Systemic review of studies in the US and Canada. Int J Tuberc Lung Dis 2008;12:1235-54.

3. Hirsch-Moverman Y, Bethel J, Colson PW, Granks J, El-Sadr W. Predictors of latent tuberculosis infection treatment completion in the United States: An inner city experience. Int J Tuberc Lung Dis 2010;14:1104-11.

4. Bock N, Metzger B, Tapia JR, Blumberg HM. A tuberculin screening and isoniazid preventative therapy program in an inner city population. Am J Respir Crit Care Med 1999;159:295-300.

5. Horsburgh CR, Goldberg S, Bethel J, et al. Latent TB infection treatment acceptance and completion in the United States and Canada. Chest 2010;137:401-9.

6. Kwara A, Herold JS, Machan JT, Carter EJ. Factors associated with failure to complete isoniazid treatment for latent tuberculosis infection in Rhode Island. Chest 2008;133:862-8.

7. Nyamathi AM, Christiani A, Nahid P, Gregson P, Leake B. A randomized controlled trial of two treatment programs for homeless adults with latent tuberculosis infection. Int J Tuberc Lung Dis 2006;10:775-82.

8. Shieh FK, Synder G, Horsburgh CR, Bernardo J, Murphy C, Saukkonen JJ. Predicting non completion of treatment for latent tuberculous infection. Am J Resp Crit Care Med 2006;174:717-21.

9. Canadian lung association/Canadian Thoracic Society. Canadian Tuberculosis Standards, 6th edn. 2007:1-450.

10. Chaisson RE, Barnes GL, Hackman J, et al. A randomized, controlled trial of interventions to improve adherence to isoniazid therapy to prevent tuberculosis in injection drug users. Am J Med 2001;110:610-5.

11. Edmonton, Alberta (Code835) (table). 2006 Community Profiles. 2006 Census. Statistics Canada Catalogue no. 92-591-XWE. Ottawa. Released March 13, 2007. <www12.statcan.ca/censusrecensement/2006/dp-pd/prof/92-591/index.cfm?Lang=E $>$ (Accessed March 26, 2012).

12. 2010 Annual Report. Edmonton (Alberta, Canada): Homeward Trust Edmonton; 2010:1-36.

13. McNab BD, Marciniuk DD, Alvi RA, Tan L, Hoeppner VH. Twice weekly isoniazid and rifampin treatment of latent tuberculosis infection in Canadian Plains Aborigines. Am J Respir Crit Care Med 2000;162:989-93.

14. Nuzzo JB, Golub JE. Analysis of latent tuberculosis infection adherence among refugees and other patient groups referred to the Baltimore City Health Department TB clinic, February 2009 March 2011. J Immigrant Minority Health. August 2, 2013 (Epub ahead of print). the service adequately. This highlights the need to improve health care and housing strategies for the homeless.

Our study had several limitations. The small number of cases among homeless individuals limits the strength of our findings. The small sample size also limits the generalizability of our findings to other populations. Despite our success in treatment completion, the transient nature of homeless populations remains a challenge to our ability to provide intensive case management and tracking which is the cornerstone of our outreach strategy. This challenge underscores the need for innovative health care delivery strategies that meet the needs of homeless populations, the need for further studies addressing adherence interventions in this population and the need for greater efforts to decrease homelessness.

\section{CONCLUSION}

Improved treatment completion rates of LTBI among an inner-city cohort of patients is possible with intensive case management combining tracking, education, incentives and health promotion. However, homelessness remains a significant barrier, suggesting the need for improved health care delivery and housing strategies for this population.

15. Li J, Munsiff SS, Tarantino T, Dorsinville. Adherence to treatment of latent tuberculosis infection in a clinical population in New York City. Int J Inf Dis 2010;14:e292-e297.

16. LoBue PA, Moser KS. Use of isoniazid for latent tuberculosis infection in a public health clinic. Am J Respir Crit Care Med 2003;168;443-7.

17. Tulsky JP, Pilote L, Hahn JA, et al. Adherence to isoniazid prophylaxis in the homeless: A randomized controlled trial. Arch Intern Med 2000;160:697-702

18. Codecasa LR, Murgia N, Farrarese M, et al. Isoniazid preventive treatment: Predictors of adverse events and treatment completion. Int J Tuberc Lung Dis 2013;17:903-8.

19. Bamrah S, Yelk Woodruff RS, Powell K, Ghosh S, Kammerer JS, Haddad MB. Tuberculosis among the homeless, United States, 1994-2010. Int J Tuberc Lung Dis 2013;17:1414-9.

20. Figueroa-Munoz JI, Ramon-Pardo P. Tuberculosis control in vulnerable groups. Bull World Health Organ 2013. <www.who.int/ bulletin/volumes/86/9/06-038737/en/> (Accessed February 11, 2014)

21. Hwang SW. Homelessness and health. CMAJ 2001;162:229-33.

22. Althomsons SP, Kammerer JS, Shang N, Navin TR. Using routinely reported tuberculosis genotyping and surveillance data to predict tuberculosis outbreaks. PLoS ONE 2012;7:e48754.

23. Lindquist S, Allen S, Field K, et al. Prioritizing tuberculosis genotype clusters for public health action - Washington State. Emerg Infect Dis 2013;19:493-6.

24. Hwang SW, Ueng JJ, Chiu S, et al. Universal Health Insurance and Health Care Access for Homeless Persons. Am J Public Health 2010;100:1454-61.

25. Gelberg L, Gallagher TC, Andersen RM, Koegel P. Competing priorities as a barrier to medical care among homeless adults in Los Angeles. Am J Public Health 1997;87:217-20.

26. Ku BS, Scott KC, Kertesz SG, Pitts SR. Factors associated with use of urban emergency departments by the U.S. homeless population. Public Health Rep 2010;125:398-405.

27. Kushel MB, Vittinghoff E, Haas JS. Factors associated with health care utilization of homeless persons. JAMA 2001;285:200-6.

28. Darkwah V, Yamane H, Richter S, et al. A systematic review on the intersection of homelessness and healthcare in Canada. J Nurs Care 2012;1:5

29. Lashley M. A targeted testing program for tuberculosis control and prevention among Baltimore City's homeless population. Public Health Nurs 2007;24:34-9.

30. Kwara A, Herold JS, Machan JT, Carter EJ. Factors associated with failure to complete Isoniazid treatment for latent tuberculosis infection in Rhode Island. Chest 2008;133:862-8. 


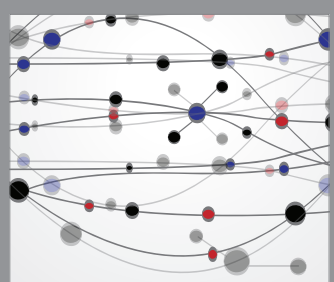

The Scientific World Journal
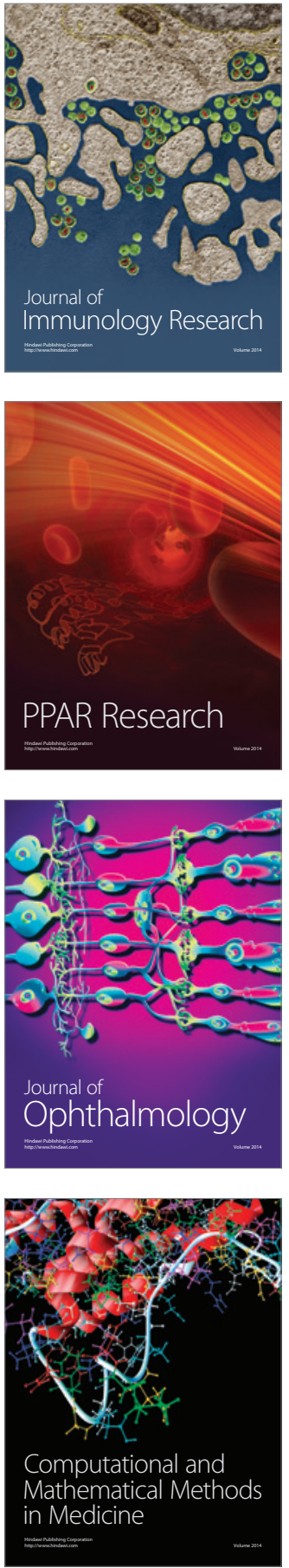

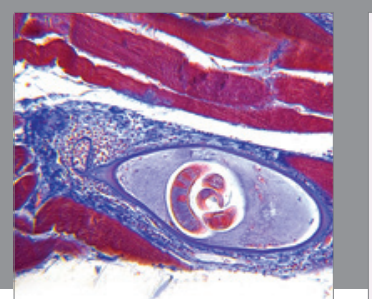

Gastroenterology Research and Practice

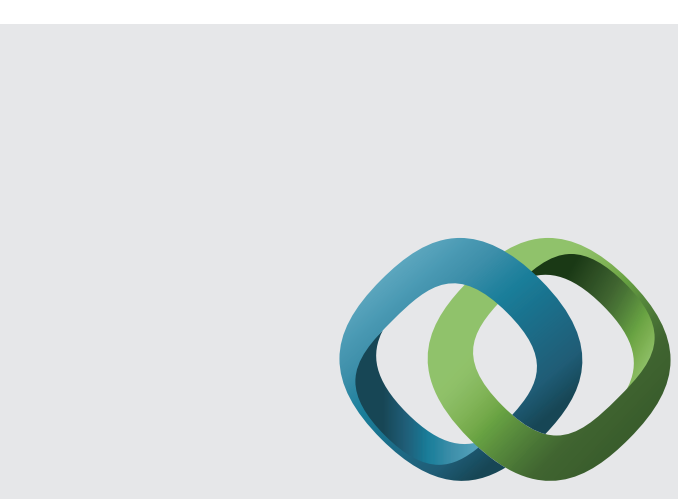

\section{Hindawi}

Submit your manuscripts at

http://www.hindawi.com
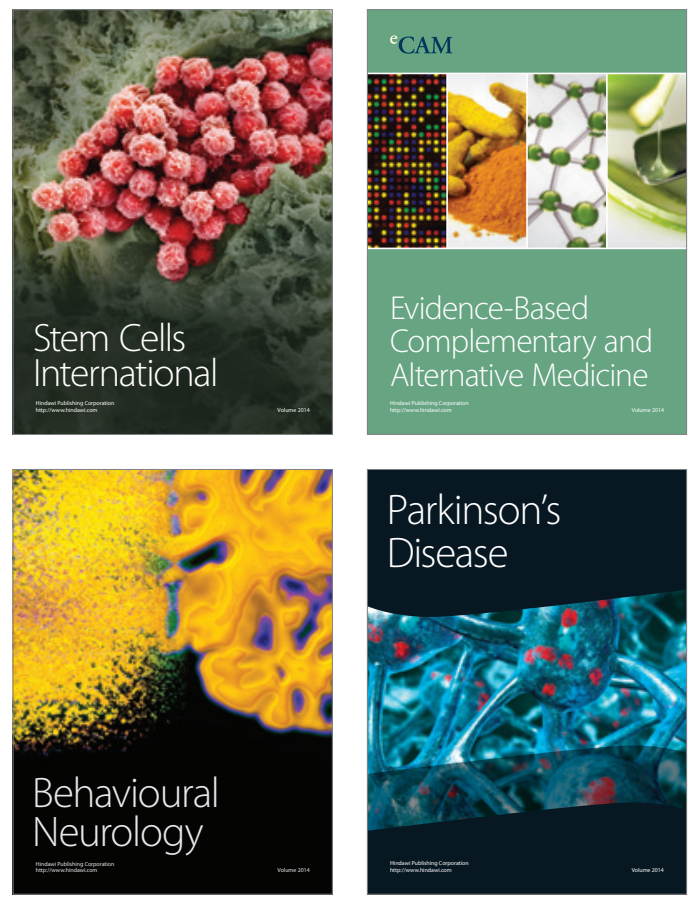
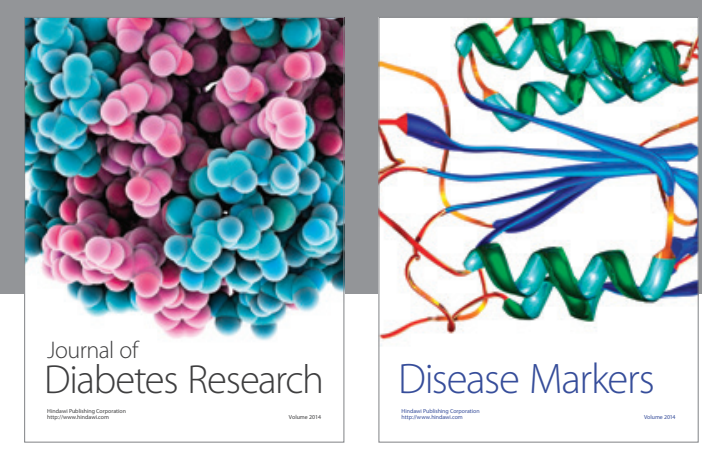

Disease Markers
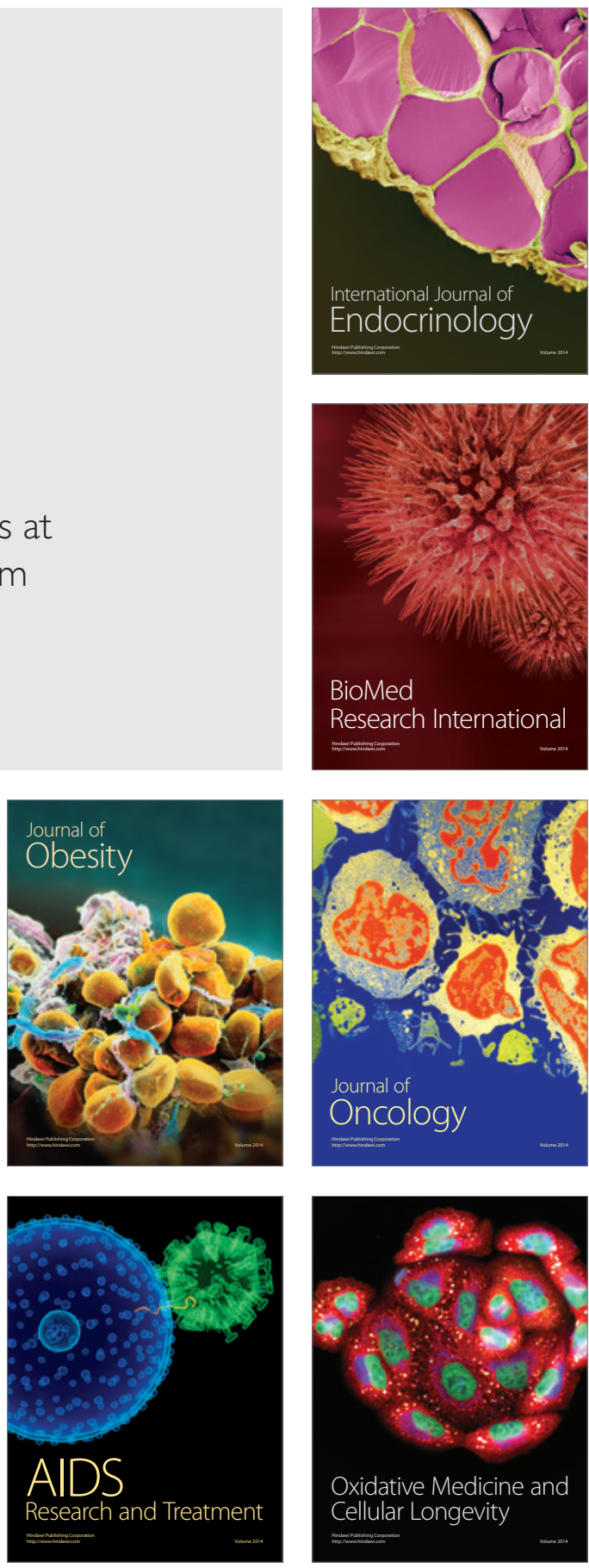